\title{
A Scrutiny on Differential Calculus in Criminology and Forensic Science
}

\author{
S. SathyaPriya1, R. Ramya Priya², R. Deepa² \\ ${ }^{1}$ Assistant Professor, 2 UG Scholar \\ 1,2Department of Mathematics, Sri Krishna Arts and Science College, Coimbatore, Tamil Nadu, India
}

\begin{abstract}
\section{INTRODUCTION}

CRIMINOLOGY

Criminology is a combination of two Latin words : Crimen crime Logus or logy - science. It is the science or study of crime. It is concerned with the conduct of individuals which is prohibited by society and law. It is a socio-legal study which seeks to discover the causes of criminality and suggests appropriate remedies.
\end{abstract}

Using mathematical methods to understand and model crime is a recent idea that has drawn considerable attention from researchers during those years. From the plethora of models that have been proposed, perhaps the most successful one has been a diffusion-type differential equations model that describes how the number of criminals evolves in a specific area. We propose a more detailed form of this model that allows for two distinct criminal types associated with major and minor crime. Newton's Law of Cooling also supports the model's potential to describe crime.

\section{CRIME SCENE INVESTIGATION}

A crime scene is any physical scene, anywhere, that may provide potential evidence to an investigator. It may include a person"s body, any type of building, vehicles, and places in the open air or objects found at those locations. "Crime scene examination" therefore refers to an examination where forensic or scientific techniques are used to preserve and gather physical evidence of a crime. Crime Scene Investigation gather fingerprints, blood, bodily fluids, and other evidence found at the crime scene in order to solve a crime or even determine whether a crime has taken place. Investigating a crime scene can be a very long, tedious process that should be completed by a trained professional with excellent attention to detail. It not only encompasses collection of evidence, but also the necessary analysis to ensure that the evidence is credible and relevant. Investigating a crime scene is one of the most important parts of any criminal investigation. If done right, it can actually be the key to solving a crime. Crime Scene Investigators, or CSIs, use special methods and equipment for investigating a crime scene. These methods include using certain type of equipment, special investigation methods, and most importantly, preserving the integrity of a crime scene so that nothing gets moved or disturbed. Investigating how a crime occurred can offer a lot of insight into why the crime occurred at all. Since evidence gathered at a crime scene is what puts a criminal in jail, crime scenes are very important. There are many steps that have to be taken when conducting a criminal investigation and investigating a crime scene. Firstly, detectives have to try and figure out why and how a crime was committed. They examine a crime scene looking for information or clues such as fingerprints, weapons, and DNA. They investigate the victims" history to determine why someone would want to harm them. After they have formed a hypothesis, they try to find proof that somebody committed a crime so that they can arrest the suspects. They look at both the motive and the actual evidence of the crime and try to see if their hypothesis makes sense. The suspects then enter the criminal justice system where they are tried using the evidence collected at the crime scene. Crime scene investigators have special equipment that they use to investigate crime scenes. This equipment is packed into crime scene kits. They include fingerprint powders designed to find fingerprint on surfaces, brushes, magnetic power wands, and placards for marking important evidence, tape, scissors, tweezers, tape, pencils, and pens. They also include chemicals for detecting bodily fluids like luminal and black lights.

\section{FORENSIC SCIENCE}

Forensic science is the application of science to criminal and , civil law mainly - on the criminal side-during criminal investigation, as governed by the legal standards of admissible evidence and criminal procedure. Forensic scientists collect, preserve, and analyze scientific evidence during the course of an investigation. While some forensic scientists travel to the scene of the crime to collect the evidence themselves, others occupy a laboratory role, performing analysis on objects brought to them by other individuals.

In addition to their laboratory role, forensic scientists testify as expert witnesses in both criminal and civil cases and can work for either the prosecution or the defense. While any field could technically be forensic, certain sections have developed over time to encompass the majority of forensically related cases. Forensic science is the combination of two different Latin words: forensis and science. The former, forensic, relates to a discussion or examination performed in public. Because trials in the ancient world were typically held in public, it carries a strong judicial connotation. The second is science, which is derived from the Latin word for knowledge and is today closely tied to the scientific method, a systematic way of acquiring knowledge. Taken together, then, forensic science can be seen as the use of the scientific methods and processes in crime solving.

\section{NEWTON'S LAW OF COOLING}

The Newton's Law of Cooling model computes the temperature of an object of mass $\mathrm{M}$ as it is heated by a flame 
and cooled by the surrounding medium. The model assumes that the temperature $\mathrm{T}$ within the object is uniform. This lumped system approximation is valid if the rate of thermal energy transfer within the object is faster than the rate of thermal energy transfer at the surface. Newton's law of cooling states that the rate at which a warm body cools is approximately proportional to the difference between the temperature of the warm object and the temperature of its environment. Newton's law of cooling is generally limited to simple cases where the mode of energy transfer is convection, from a solid surface to a surrounding fluid in motion, and where the temperature difference is small, approximately less than $10^{\circ} \mathrm{C}$ (The Encyclopedia Britannica, 1910).When the medium into which the hot body is placed varies beyond a simple fluid, such as in the case of a gas, solid, or vacuum, etc., this becomes a residual effect requiring further analysis (Whewell , 1866).

\section{PROBLEMS}

1. The temperature of a corpse approximately obeys. Newton's law of cooling, which states that the rate of change in temperature in the body is proportional to the difference in temperature from room temperature. If a body is found in a temperature controlled room set at $62^{\circ} \mathrm{F}$ and the temperature measures at 9:00 pm measures $90{ }^{\circ} \mathrm{F}$ and is decreasing at an instantaneous rate at $2^{\circ} \mathrm{F}$ per hour, estimate a time of death.

\section{SOLUTION}

Given

Temperature of body $\mathrm{T}$

Time of day( $\mathrm{t}(9: 00 \mathrm{pm} \mathrm{t}=>9)(\mathrm{t}=0$ noon $)$

By newton's law of cooling,

$\frac{d T}{d t}=K(T-62)$

$\frac{d T}{d t}=K T-62 T$

Temperature difference:

$D=T-62$ (difference in temperature)

$\frac{d D}{d t}=\frac{d}{d t}(T-62)$

$$
=\frac{d T}{d t}=k D
$$

By given information,

$$
\begin{gathered}
t=y \\
T=90=>D=T-62 \\
D=90-62 \\
D=28 \\
\frac{d T}{d t}=-2=>\frac{d D}{d t}=-2 \\
\frac{d D}{d t}=K D=>-2=K(28) \\
->K--1 / 14 \\
D=A e-t / 14 \\
D(9)=28=A e-9 / 14
\end{gathered}
$$

$$
\begin{gathered}
=>A=28 e 9 / 14 \\
D(t)=28 e y / 14 e-t / 14 \\
=28 e(9-t) / 14
\end{gathered}
$$

When did he die?

$$
\begin{gathered}
D(t)=98.6-62 \\
28 e(9-t) / 14=36.6 \\
D(t)=28 e(9-t) / 14=36.6 \\
e(9-t) / 14=36.6 / 78 \\
9-t / 14=\log (36.6 / 28) \\
9-t=14 \log (36.6 / 20) \\
t=9-14 \log (36.6 / 28) \\
t=9-14(0.1163) \\
t=9-1.6282 \\
t=7.37 \\
t=7 \frac{2}{5} \text { hours }
\end{gathered}
$$

The time of death is $7.20-7.25 p m$

2. At 10:07pm, you find a secret agent murdered. Next to him is a martini that got shaken before the secret agent could stir it. Room temperature is $90^{\circ} \mathrm{F}$. The martini warms from $80^{\circ} \mathrm{F}$ to $81^{\circ} \mathrm{F}$ in the 2 minutes from $10: 07 \mathrm{pm}$ to $10: 09 \mathrm{pm}$.If the secret agent's martinis are always served at $50^{\circ} \mathrm{F}$. What was the time of death?

\section{SOLUTION}

By Newton's law of cooling,

$\frac{d T}{d u}=K(T-T s)$

$$
\begin{gathered}
\frac{d T}{d t}=K(T-90) \\
d T=K(T-90) d t \\
d T=K(T-90) d t \\
\frac{d T}{K(T-90)}=d t
\end{gathered}
$$

Integrating on both sides,

$$
\int \frac{d T}{K(T-90)}=\int d t
$$

$\frac{1}{K} \int \frac{d r}{(r-90)}=\mathrm{t}+\mathrm{c}$

Taking $\mathrm{u}=\mathrm{T}-90$

Differentiating w.r.t T,

$\frac{d u}{d T}=1$

$$
\begin{gathered}
d u=d T \\
\frac{1}{K} \log (T-90)=t+c \\
\log (T-90)=K t+c
\end{gathered}
$$


Taking on both sides,

$$
\begin{gathered}
(T-90)=e^{(K t+c)} \\
(T-90)=e^{K t} e^{e} \\
(T-90)= \pm e^{K t} e^{e} \\
T-90=m e^{K t}
\end{gathered}
$$

At, $T(0)=80, t=0$

$$
\begin{gathered}
80-90=m e^{K t} \\
m=-10 \\
T-90=-10 e^{K t} \\
A t_{,} T(1)=81, t=2 \\
81-90=-10 e^{2 K} \\
-9=-10 e^{2 K} \\
\frac{9}{10}=\epsilon^{2 K}
\end{gathered}
$$

Taking log on both sides,

$$
\begin{gathered}
\log \left(\frac{9}{10}\right)=2 K \\
\frac{\log \left(\frac{9}{10}\right)}{2}=K \\
T-90=-10 e^{\log \left(\frac{9}{10}\right) \frac{t}{2}} \\
T(t)=-10 e^{\log \left(\frac{9}{10}\right) \frac{t}{2}}+90 \\
50=-10 e^{\log \left(\frac{9}{10}\right) \frac{t}{2}+90} \\
\frac{50-90}{-10}=e^{\log \left(\frac{9}{10}\right) \frac{t}{2}} \\
\frac{-40}{-10}=e^{\log \left(\frac{9}{10}\right) \frac{t}{2}} \\
4=\left(\frac{9}{10}\right) \frac{t}{2} \\
\log 4=\frac{t}{2} \log \left(\frac{9}{10}\right) \\
2\left(\frac{\log 4}{\log \frac{9}{10}}\right)=t \\
2\left(\frac{0.6021}{-0.0458)}\right)=t \\
2(-13.147)=t \\
t--26.294 \\
t=-26
\end{gathered}
$$

Therefore, the secret agent was murdered at 9:41pm.

3. A homicide victim is found at $6: 00 \mathrm{pm}$ in an office building that is maintained at $72^{\circ} \mathrm{F}$. when the victim was found, his body temperature was at $85^{\circ}$ F.Three hours later at 9:00pm, his body temperature was recorded at $78^{\circ} \mathrm{F}$. Assume the temperature of the body at the time of death is your typical normal temperature of $98.6^{\circ} \mathrm{F}$.

\section{SOLUTION}

Given,

The equation for the temperature,$\theta$ of the body is,

$$
\frac{d \theta}{d t}=-k(\theta-\theta a)
$$

Where,

$\theta \rightarrow$ temperature of the body, ${ }^{\circ} \mathrm{F}$

$\theta a \rightarrow$ ambient temperature, ${ }^{\circ} \mathrm{F}$

$t \rightarrow$ time.hours

$k \rightarrow$ constant

$$
\begin{aligned}
& \frac{d \theta}{d t}=-k(\theta-\theta a) \\
& \frac{d \theta}{d t}+k \theta=-k \theta a
\end{aligned}
$$

The characteristic equation of the above ordinary differential equation is,

$$
\begin{gathered}
m+k=0 \\
m=-k \\
\theta_{\mathrm{H}}=\mathrm{A}^{-k t}
\end{gathered}
$$

The particular solution is of the form,

$\theta_{\mathrm{p}}=\mathrm{B}$

Substituting the form of the solution in the ordinary differential equation,

$\theta+\mathrm{kB}=\mathrm{K} \theta_{a}$

$\mathrm{B}=0 \mathrm{a}$

Given, $\theta a=72$

$\theta(6)=85$

$\theta(9)=78$

$\theta(B)=98.6$

Where, $B=$ time of death

We get,

$85=\mathrm{A} e^{-k 6}+72 \rightarrow 1$

$78=\mathrm{A} e^{-k 9}+72 \rightarrow 2$

$98.6=\mathrm{A} e^{-k B}+72 \rightarrow 3$

Using equation $1 \& 2$, to find $\mathrm{A}$ and $\mathrm{K}$,

$85=\mathrm{A} e^{-k 6}+72$

$\mathrm{A} e^{-k 6}=13 \quad \rightarrow 4$

$78=\mathrm{A} e^{-k 9}+72$

$\mathrm{A} e^{-k 9}=6 \rightarrow 5$ 
Dividing equation 5 by equation 4,gives,

$$
\begin{gathered}
\mathrm{Ae}^{-k 6}=13 \\
\mathrm{~A} e^{-k 9}=6 \\
e^{5 k}=2.16667
\end{gathered}
$$

$\mathrm{k}=0.25773$

knowing the value of $\mathrm{k}$, from equation 5 ,

$\mathrm{A}=61.028$

Substituting $\mathrm{k}$ and $\mathrm{A}$ into equation 3 ,to find $\mathrm{B}$,

$98.6=\mathrm{A} e^{-k E}+72$

$98.6=61.028 e^{-0.25773 .5}+72$

$26.6=61.028 e^{-0.25773 B}$

$\log 26.6=\log 61.028-0.25773 \mathrm{~B}$

$0.25773 \mathrm{~B}=0.83042$

$\mathrm{B}=3.2221$

The time of death is 3.2221 , that is $0.2221 * 60=13.326$ minutes after $3 \mathrm{pm}$.

The time of death $=3: 13 \mathrm{pm}$

4. The coroner arrives on a scene of a homicide at $10 \mathrm{pm}$ in a $70^{\circ}$ room. She takes the temperature of the body and gets $92.4^{\circ}$. It takes her 30 minutes to perform some other duties. She then takes the temperature again and finds it is now $91.8^{\circ}$.Estimate the time of death of this homicide.

\section{SOLUTION}

$(91.8-70)=(92.4-70) e^{-k(30)}$

$21.8=22.4 e^{-30 k}$

$$
\frac{\log \left(\frac{21.8}{22.4}\right)}{-30}=k=0.0009
$$

$(92.4-70)=(98.6-70) e^{-0.0009 t}$
$22.4=28.6 e^{-0.0009 t}$

$\frac{\log \left(\frac{28.4}{28.6}\right)}{-0.0039}=t=271 \mathrm{~min}$

$\mathrm{t}=4 \mathrm{hrs} 31 \mathrm{~min}=5: 29 \mathrm{pm}$

The time of death is $5: 29 \mathrm{pm}$

\section{CONCLUSION}

Variables such as posture of the body, site of reading of the post mortem body temperature, emaciation and microenvironment (rain, humidity etc) that were not considered in this thesis for the determination of time of death could be study to improve the current model to account for the long post mortem period and to accurately estimate time of death. This improvement can be used for scientific crime investigation.

\section{REFERENCE}

[1] Green, M.A., Wright, J.C. (1985), Postmortem interval estimation from body temperature data only. Forensic Sci Int .

[2] Henssge, C. (1979), Zeitschrift fur Rechtsmedizin. Journal of Legal Medicine Precision of estimating the time of death by mathematical expression of rectal body cooling.

[3] Leinbach, C. (2011), Beyond Newton's Law of Cooling Updated Methods for Estimating time since Death.

[4] Marshall, T.K. and Hoare, F.E. (1962), Estimating the time of death. The rectal cooling after death and its mathematical expression, Journal of Forensic Sciences 7,5681.

[5] Brown, A. and Marshall, T.K. (1974), Body temperature as a means of estimating the time of death.

[6] https://www.google.com/search?client=firefox$\mathrm{bd} \& \mathrm{q}=$ newtons+law $+\mathrm{of}+$ cooling

[7] https://study.com/academy/lesson/the-rational-choicetheory-of-criminology.html

[8] https://www.youtube.com/watch?v=zB5Zr97Io28

[9] https://en.wikipedia.org/wiki/Newton\%27s_law_of_cool ing 